\title{
Treatment related Psycho-Social Needs of Persons with Complicated Alcohol Withdrawal in Delirium Tremens: a Qualitative Enquiry from India
}

\author{
Julian A.J. Arthur ${ }^{1}$, R. Dhanasekara Pandian², Pratima Murthy ${ }^{3}$ \\ ${ }^{1}$ Ph.D Scholar, Department of Psychiatric Social Work, National Institute of Mental Health and Neurosciences \\ (NIMHANS), Bangalore, India. \\ ${ }^{2}$ Additional Professor, Department of Psychiatric Social Work, National Institute of Mental Health and Neurosciences \\ (NIMHANS), Bangalore, India. \\ ${ }^{3}$ Professor of Psychiatry, Centre for Addiction Medicine, Department of Psychiatry, National Institute of Mental \\ Health and Neurosciences (NIMHANS), Bangalore, India. \\ E-mail - vnrpandian@gmail.com
}

\begin{abstract}
Background: Understanding the needs of clients seeking treatment for addiction related disorders plays a vital role in treatment outcomes. Alcohol Dependence Syndrome (ADS) is known to impact individuals along with their family members. However, there is a paucity of literature in the Indian context on the treatment needs of persons with ADS. The present study aimed to explore the treatment related felt needs of persons who presented with complicated Alcohol Withdrawal in Delirium Tremens (CAWDT).

Methods: Semi-structured interviews were conducted with 25 males who presented with CAWDT at the Centre for Addiction Medicine (CAM), National Institute of Mental Health and Neuro Sciences (NIMHANS), a tertiary health care centre in Bangalore, Karnataka, India. The interviews were recorded, transcribed and analyzed using the General Inductive approach.

Results: The mean age of the sample was 36.28 years and their total duration of dependence on alcohol was 12.96 years. From the qualitative data analysis, five 5 broad categories of needs emerged, which were: (i) managing craving and relapse, (ii) personal needs, (iii) informational needs, (iv) cognitive needs and (v) miscellaneous needs such as health related needs, financial help and counselling needs.

Conclusion: Patients with CAWDT are a very vulnerable group where repeated withdrawal from alcohol can lead to severe complications including death, making it imperative to address their concerns comprehensively. Assessing and addressing these needs in treatment will help in better treatment outcomes as well as help in developing and personally tailoring psycho-social interventions for better and holistic management.
\end{abstract}

Key Words: Alcohol, Complicated Withdrawal, Delirium Tremens, Needs, Qualitative.

(Paper received $-14^{\text {th }}$ March 2017, Peer review completed -28 th $^{\text {th }}$ March 2017, Accepted $-30^{\text {th }}$ March 2017)

\section{INTRODUCTION}

Alcohol Dependence is defined as 'a cluster of behavioural, cognitive, and physiological phenomena that develop after repeated alcohol use and that typically include a strong desire to consume alcohol, difficulties in controlling its use, persisting in its use despite harmful consequences, a higher priority given to alcohol use than to other activities and obligations, increased tolerance, and sometimes a physiological withdrawal state' [1]. Alcohol withdrawal delirium (Delirium Tremens, DT), is a severe complication which may be preceded or complicated by seizures [1]. Literature in India is scarce as highlighted in a review that DT is not given importance in teaching programmes, research protocols and therapeutic strategies [2].

Indian Journal of Mental Health 2017;4(1) 
Pharmacological management has been extensively reported [3]. It is just the start towards abstinence and extends into enrolling in long term treatment programmes [4]. However, literature on nonpharmacological interventions is lacking [5]. Patients face multiple problems apart such as depression, unemployment, financial and family problems, limited social support [6], psycho-social problems in the form of medical needs, psychological distress, legal involvement, employment problems, and/or housing difficulties [7]. Researchers [8] have identified several unmet needs such as financial, mental health, vocational and medical service needs, which are known to be closely related to alcohol use and have negative impacts on treatment retention and outcome [9].

Though treatment services have acknowledged clients' multiple needs and improved the service diversity, few comprehensive programs exist [10]. This creates a growing need to match patients to specific treatment modalities [11]. Treatment programmes usually provide only basic services and occasionally supplemented with adjunct services or a mixture of different service [12]. For holistic treatment, the selection of appropriate treatments based on their need would facilitate a positive and lasting outcome. Such an exploration of needs has not been undertaken for persons with Complicated Alcohol Withdrawal in Delirium Tremens (CAWDT), prompting the present study at a tertiary care addiction treatment facility of southern India.

\section{METHODOLOGY}

\section{Ethical statement}

This study is part of the initial phase of an ongoing doctoral study titled "Intensive case management for persons with severe alcohol dependence: a feasibility study (Clinical Trials Registry India no: CTRI/2015/02/005564)." The ethical approval was obtained from the institutional Human Ethics Committee. The patients were explained about the study and written informed consent was obtained.

\section{Design}

This qualitative explorative study used semi-structured face-to-face interviews for data collection and followed a general inductive approach for data analysis [13]. This approach proposes simple steps in qualitative data analysis, which summarizes large raw textual data into concise results, and establishes clear relationships with research objectives [13].

\section{Setting and participants}

The study was carried out at the Centre for Addiction Medicine, NIMHANS, Bengaluru, Karnataka, India. Male patients aged $\geq 18$ years to 50 years; diagnosed with ADS as per the International Classification of Diseases (ICD-10), presenting with CAWDT, able to converse in either English or Kannada; and not using any other substance (except nicotine were included). Persons with co-morbid or unstable medical or neurological conditions were excluded. Of the 41 eligible patients contacted during the months of June 2015 to December 2015, 25 eligible patients who consented to participate for this phase of the study were included. To generate a comprehensive set of needs - a heterogeneous group of respondents was purposively selected and included into 3 groups - first time treatment seekers for CAWDT $(\mathrm{N}=10)$, those maintaining abstinence at one month follow-up $(\mathrm{N}=7)$ and those re-admitted with an early relapse following initial treatment $(\mathrm{N}=8)$.

\section{Interviews and data collection}

Socio-demographic and clinical related details were collected using a standardized schedule. Once the patients had recovered from the episode of DT, and cognitive abilities had improved, as ascertained by a qualified psychiatrist, face-to-face interviews were conducted by the first author (JAJA) focusing on understanding their needs. Open-ended questions were asked such as, "What are your current needs and concerns? Or what kind of help are you expecting from the doctors?" If they could not respond spontaneously they were assisted with probes that were prepared in consultation with eight mental health professionals belonging to Psychiatric Social Work (3), Psychiatry (3), Psychology (2) and Anthropology 
(1) disciplines. They were selected based on their experience in working in the field of addiction medicine or possessing the knowledge of qualitative research methods.

\section{STATISTICAL ANALYSIS}

The 25 audio recordings were transcribed into English text and field observation notes were added. Later the transcripts were imported into and coded with the assistance of QDA Miner Lite (http://provalisresearch.com/products/qualitative-data-analysis-software/freeware/). A single researcher is sufficient to carry out the analysis if they are well immersed in the process of data collection and analysis, $[14,15]$ which was carried out by the first author (JAJA). The general inductive approach [13] was used to a guide the qualitative data analysis. During coding, the text segments that depicted the needs were critically analyzed and codes were created initially for ten transcripts. It was revised, refined with new insights, checked for consistency and later assigned under the meaningful themes. This was further discussed with two peer researchers to sort out and cross-check the consistency of the codes with the assigned themes. The differences were resolved after clarifications and discussion. Though saturation was achieved at 18 interviews the analysis for all 25 interviews was completed.

\section{RESULTS}

\section{Socio-demographic data and clinical characteristics of the patients with CAWDT}

The mean age of the patients was 36 years $(S D \pm 6.3)$ and they had a mean of 7 years $(S D \pm 4.15)$ of education. Majority (60\%) belonged to lower / upper middle class; were Hindus and married $(\mathrm{N}=21)$ and unskilled by profession $(\mathrm{N}=11)$. The clinical characteristics are presented in Table 1.

Table 1 - Clinical Profile of patients with CAWDT

\begin{tabular}{|cc|}
\hline VARIABLE & Mean \pm SD \\
\hline Age at initiation of first use of alcohol & $19.48 \pm 4.35($ Median $=19)$ \\
\hline Age at first intoxication & $20.28 \pm 4.70($ Median $=20)$ \\
\hline Age at initiation of daily drinking of alcohol & $23.36 \pm 4.86($ Median $=25)$ \\
\hline Age of harmful use of alcohol & $23.68 \pm 4.69($ Median $=25)$ \\
\hline Age of onset of dependence on alcohol & $23.80 \pm 4.62($ Median $=25)$ \\
\hline Total Duration of Dependence in years & $12.96 \pm 7.73($ Median $=12)$ \\
\hline Duration of untreated dependence in years & $12.24 \pm 7.90($ Median $=10)$ \\
\hline $\begin{array}{c}\text { Amount of money spent on alcohol consumption } \\
\text { in a day }\end{array}$ & $272 \pm 97.98($ Median $=300)$ \\
\hline Recovery from the DT episode in days & $4.04 \pm 1.02($ Median $=4)$ \\
\hline Number of In-patient admission days & $19.12 \pm 7.51($ Median $=17)$ \\
\hline Maximum period of Abstinence in months & $4.80 \pm 2.78($ Median $=4)$ \\
\hline
\end{tabular}

\section{Treatment related Psycho-social felt needs of the patients with CAWDT}

Five themes emerged from the qualitative data analysis. The needs are organized and presented under the relevant themes as per the hierarchy based on the number of times the patients emphasized on each need (See Table 2). The detailed description of each theme and the participants' quotes are given below:

\section{Managing Craving and Relapse Prevention}

Patients wanted help in handling craving, managing peer pressure, time and money that posed as maintaining factors for relapse based on their previous experiences. Their quotes are as follows:

"I don't know what to do even when I know that I should not drink, I feel like drinking. Even after taking medication I get this feeling (craving). I try my best but I am unable to handle it.... I need your [professional] help." (Participant 1 , 32 years) 
"When I meet my friends, they force me to accompany them. Even though I tell them that I have stopped drinking they compel me. The doctors say that we should avoid meeting them but I, do not know how to manage this situation. Can you tell me how I can meet my friends without drinking?" (Participant 4, 28 years)

"After completing a project, the first thing that I want to do is to go and drink... I want to know how to manage my money because when I have extra money, I drink to celebrate my achievement and as a way to relax." (Participant 10, 34 years)

\section{Personal Needs}

Persons with CAWDT were expressive about their personal needs. Few of them denied the problem while others attributed their drinking as a result of the behaviour of their family members.

"There is a lot of misunderstanding between me and my wife for simple reasons...leading to verbal fights. My wife says she will leave me if I drink so I get upset.... I know my drinking is a problem but I cannot control myself...I need you [professionals] to help us to solve these problems." (Participant 2, 35 years)

"When I come home late or if I am out with friends, she criticizes me saying that I started drinking....this upsets me a lot. In the past I used to go and drink.... I only wish if my wife could understand what I am going through and stop doubting me." (Participant 22, 31 years)

"I face a lot of pressure both personally and professionally. I am unable to work properly or spend time with my family. All these things disturb me and I feel stressed so I end up drinking...I want to know how I can manage all these problems." (Participant 11, 36 years)

Table 2 - Hierarchy of needs of Patients with CAWDT

\begin{tabular}{|c|c|c|c|}
\hline Hierarchy & Themes & $\begin{array}{l}\text { No. of } \\
\text { participants }\end{array}$ & Codes \\
\hline 1 & $\begin{array}{c}\text { Managing Craving } \\
\text { and relapse } \\
\text { prevention }\end{array}$ & 23 & $\begin{array}{l}\text { Handling craving; handling peer pressure; } \\
\text { managing high risk situations, money and } \\
\text { time management; handling } \\
\text { feelings/emotions. }\end{array}$ \\
\hline 2 & Personal needs & 22 & $\begin{array}{l}\text { Addressing marital \& family problems; } \\
\text { family members to be supportive and less } \\
\text { critical/nagging and doubting; handling } \\
\text { problems at work place. }\end{array}$ \\
\hline 3 & Information needs & 19 & $\begin{array}{l}\text { Information about effects and impact of } \\
\text { alcohol; treatment; causes; side effects of } \\
\text { medication; follow up; investigations and } \\
\text { want material on the same. }\end{array}$ \\
\hline 4 & Cognitive needs & 16 & $\begin{array}{l}\text { Improvement in thinking, improvement in } \\
\text { memory and concentration as well. }\end{array}$ \\
\hline 5 & Miscellaneous needs & 12 & $\begin{array}{l}\text { Help in providing free medication \& } \\
\text { treatment; help in sleep, sexual and gastric } \\
\text { problems; need for home visits, same } \\
\text { therapist and telephone contacts }\end{array}$ \\
\hline
\end{tabular}

\section{Informational Needs}

Persons with CAWDT asked for information about the illness such as the causes, prognosis, treatment and investigations, side effects of medication and follow up.

"I do not know why this happened to me.... after stopping alcohol, I started having bad visions and my wife told me that I also got fits [seizures] but I can't remember anything. Will I become alright? Will these problems come again?" (Participant 3, 36 years) 
"The doctor said that I should take medications for 1 year, but many people say that this will affect our body. Is it okay to take medication for so long? Will there be any side effects? Suppose I drink after taking the medications, will there be any reaction?" (Participant 6,45 years)

"Could you please tell me about the result of my brain scan and liver functioning...I am very worried and want to know if it is alright or not?" (Participant 9, 42 years)

\section{Cognitive needs}

During the recovery period it was evident that the patients had cognitive problems and were in denial blaming family members for their drinking behaviour. However, they later reported of memory problems and wanted help for the same. Some of their quotes are as follows;

"Since the past few days I am having difficulties in thinking and remembering...my wife has to remind me several times...this problem never used to happen to me. Is there any treatment for improving my memory?" (Participant 16, 48 years)

"My memory is not sharp like before...my wife says that I have started to forget many simple things. I find it difficult to even remember what I had for breakfast when the doctor asks me. Is there any tonic or medication to improve my memory?" (Participant 20, 40 years)

"I find it difficult to concentrate....due to this i feel disinterested work. There have been many accidents in my factory because people were not concentrating. Is there anything that I can do to improve my concentration power?" (Participant 18, 43 years)

\section{Miscellaneous Needs}

Patients wanted to meet the same therapist and expected the doctors to spend more time with them. Few of them wanted help in addressing their financial and health related needs.

"The doctors should visit us regularly and spend more time with us. Some days the doctors will be busy with other patients and they will spend very little time with me....Even after discharge I want to consult the same doctors" (Participant 24, 50 years)

"I need your phone number Sir... I can speak to you immediately and get your help in case of any problems. I will not disturb you sir, just tell me when I can call you" (Participant 13, 30 years)

"The doctor advised me to take medications for 1 year. Each tablet costs Rupees 50 which is very costly. My family earns just enough to meet our daily needs and it will be difficult for me to buy these medications...could you please give me free medication?" (Participant 8, 34 years)

"The doctor advised me that I should get an MRI scan...it is very costly and I do not have any money with me...before coming here my wife has borrowed money from my relatives for my treatment. I don't know from where I will be able to arrange this money could you please do something" (Participant 6, 45 years)

Few of the patients requested help in addressing their health related needs:

"Ever since I got admitted I have been having difficulties in sleeping even after taking medication....sometimes even if I sleep, I get up very early and I am very tired during the whole day... the doctors say that I shouldn't sleep during the day but I find it very difficult to follow their advice. Can you please help me in this issue?" (Participant 7, 30 years)

\section{DISCUSSION}

Five major needs were identified which were: (i) Managing craving and relapse prevention, (ii) Personal needs, (iii) Informational needs, (iv) Cognitive needs, and (v) Miscellaneous needs. The needs of clients might vary across cultures and across the types of substances being abused. Managing craving and handling relapse was their foremost important need. Pharmacological treatment is just the start towards abstinence [4] and enrolling patients in treatment programmes on improving self efficacy, enhancing motivation, teaching patients coping strategies, handling craving, peer pressure and managing high risk situation have shown to be beneficial [16]. Previous episodes of complicated alcohol withdrawals [17] and impairment of executive and deficits of inhibitory control $[18,19]$ have also been known to increase the risk of relapse after detoxification. Treatment for patients in the current study is aimed at symptom management than on addressing psycho-social issues. Premature discharge from treatment, as majority of patients were daily wage workers and whose family depends on their income and psycho-social issues not 
being addressed as part of routine care, are factors hindering the process of providing psycho-social interventions. Hence most of the patients wanted this to be addressed by the doctors.

Patients reported that they wanted their family members to be supportive, less critical and not to doubt them. Several studies have reported of the impact of alcohol on a person's life leading to family problems [20], marital conflict and domestic violence [21]. In India majority of the care givers are family members [22] who play an active role in care giving. Expressed Emotion (EE) is usually associated with Schizophrenia but studies reveal that it is known to be a significant predictor for relapse in substance use disorders also [23]. High EE was seen to have a positive correlation on the frequency of relapse and shorter abstinence periods [24], which was similar to the views expressed by the patients in the current study.

Early discharge from hospital following recovery from the episode of DT leaves no time to psycho-educate patients and care givers. Patients who received an individual exposure of a videotape of their own DT, along with information about the illness showed lower relapse rate and consumed lesser alcohol [25]. Educating patients on illness related matters will help them in seeking treatment earlier [26] which was why the patients in the current study wanted information related to their problems. The fourth most important need as mentioned by the patients was in the form of experiencing cognitive difficulties such as problems with comprehension of simple tasks, poor attention and concentration, and memory difficulties. Initially the patients showed signs of cognitive impairment, as they could not comprehend nor understand the interviews. But following recovery of the episode of DT few of the patients specifically wanted help in the form of improvement in their thinking (i.e. ability to understand day to day activities), memory and being able to concentrate better. These results are in tune with individuals who experience alcohol withdrawal delirium. Chronic alcohol use is known to be associated with cognitive impairment [27]. Though prolonged use of substance is associated with greater cognitive deficits [28], few studies have demonstrated that repeated withdrawal leads to reduced brain plasticity [29] which is associated with an impairment of cognitive abilities [30] and delay in recovery from impairment in attention and executive functions [31].

Under the Miscellaneous section, patients wanted help in addressing their counselling needs, requiring financial assistance and health related needs. Alcohol use is known to be a primary cause of impairments in general health, mental and physical health [32]. Patient's with substance use disorders report of diverse needs including that of medical (physical and psychological) and financial needs, [8, 21] which is similar results of the present study. Chronic and persistent alcohol use is known to induce sexual dysfunction. The amount of alcohol consumed appeared to be the most significant predictor of developing sexual dysfunction [33] explaining why few patients perceived this need. Other findings included counselling needs where patients did not want a change in their primary therapist. Several studies have identified that therapeutic alliance between a client and therapist have shown to be significantly associated with positive treatment outcomes [34].

Patients want to participate in managing their health and stay connected with the doctor [35]. They expressed that it was difficult to come for frequent follow-ups and instead telephonic contacts would be beneficial in offering immediate respite during a crisis. Telephonic based care is known to remove such barriers [36] and provide continuity of care [37] in the form of monitoring, feedback, and counselling which have shown better results than traditional continuing care [38] which could be the reason as to why the patients requested for this.

\section{CONCLUSIONS}

The current study has some limitations where patients predominantly belonged to lower socio-economic strata of society. Time taken to recover, early discharge from treatment following recovery and cognitive abilities served as a challenge in exploring their needs. Rigorous methods in qualitative research such as multiple coders, member checks and data triangulation through FGDs could have enriched the study results further. Despite these limitations, the study has its strengths. To the best of our knowledge this is the first qualitative study that has explored the needs of persons with CAWDT from India by including participants from heterogeneous socio-demographic and clinical backgrounds. The in-depth interviews 
have added a considerable amount of strength to the study where the patients listed and ranked their needs by themselves.

Understanding patient's needs and treatment expectations can serve as a bridge in addressing their immediate concerns at the earliest resulting in better treatment outcomes'. Future implications include comparing needs of Persons with CAWDT with those of other substance use disorders and their caregivers. Further systematic qualitative studies and mixed methods can foster better understanding on this crucial aspect in the psycho-social management of persons with CAWDT. Finally, developing a programme specifically for Indian patients with CAWDT based on the needs assessment and testing them in controlled conditions is the need of the hour.

\section{REFERENCES}

1. WHO. The ICD-10 Classification of Mental and Behavioural Disorders: diagnostic criteria for research. World Health Organization: Geneva ; 1992.

2. Pinto C. Indian research on acute organic brain syndrome: Delirium. Indian J Psychiatry 2010;52(Supp1 1), S139-47.

3. Kattimani S, Bharadwaj B. Clinical management of alcohol withdrawal: A systematic review. Industr Psychiatr J 2013;22(2)100-8.

4. Blondell RD. Ambulatory detoxification of patients with alcohol dependence. Am Fam Physician 2005;71(3):495-502.

5. Mayo-Smith MF, Beecher LH, Fischer TL, Gorelick DA, Guillaume JL, Hill A, Jara G, Kasser C, Melbourne J. Management of alcohol withdrawal delirium. An evidence-based practice guideline. Arch Intern Med 2004;164(13):1405-12.

6. McLellan AT, Hagan TA, Meyers K, Randall M, Durell J. Intensive" outpatient substance abuse treatment: comparisons with "traditional" outpatient treatment. J Addict Disord 2008;16(2):57-84.

7. McLellan AT, Luborsky L, Woody GE, O'Brien CP. An improved diagnostic evaluation instrument for substance abuse patients. The Addiction Severity Index. J Nerv Ment Dis 1980;168(1):26-33.

8. D'Aunno T, Vaughn TE. An organizational analysis of service patterns in outpatient drug abuse treatment units. J Subs Abuse 1995;7(1):27-42.

9. McLellan AT, Alterman AI, Metzger DS, Grissom GR, Woody GE, Luborsky L, O'Brien CP. Similarity of outcome predictors across opiate, cocaine, and alcohol treatments: role of treatment services. J Consult Clin Psychol 2004;62(6):1141-58.

10. Polinsky ML, Hser YI, Anglin MD, Maglione MA. Drug-user treatment programs in a large metropolitan area. Subst Use Misuse 1998;33(8):1735-61.

11. Hodgson R. Treatment of alcohol problems. Addiction 1994;89(11):1529-34.

12. Hser YI, Polinsky ML, Maglione M, Anglin MD. Matching clients' needs with drug treatment services. $J$ Subst Abuse Treat 1999;16(4):299-305.

13. Thomas DR. A General Inductive Approach for Analyzing Qualitative Evaluation Data. Am J Evaluation 2008;27(2):237-46

14. Patton MQ. Enhancing the quality and credibility of qualitative analysis. Health Serv Res $1992 ; 34(5(2))$ : $1189-1208$.

15. Pope C, Ziebland S, Mays N. Analysing qualitative data. BMJ 2000;320(7227):114-6.

16. Jhanjee S. Evidence based psychosocial interventions in substance use. Indian J Psychol Med 2014;36(2): 112-8.

17. Proude E, Lapotko O, Lintzeris N, Haber P. The treatment of alcohol problems: a review of the evidence. Canberra: The Australian Government ; 2009.

18. Noel X, Paternot J, Van der Linden M, Sferrazza R, Verhas M, Hanak C, Kornreich C, Martin P, DeMol J, Pelc I, Verbanck P. Correlation between inhibition, working memory and delimited frontal area blood flow measure by 99mTc-Bicisate SPECT in alcohol-dependent patients. Alcohol Alcohol 2001;36(6):556-63.

19. Noel X, Sferrazza R, Van Der Linden M, Paternot J, Verhas M, Hanak C, Pelc I, Verbanck P. Contribution of frontal cerebral blood flow measured by $(99 \mathrm{~m}) \mathrm{Tc}$-Bicisate spect and executive function deficits to predicting treatment outcome in alcohol-dependent patients. Alcohol Alcohol 2002;37(4):347-54.

20. Room R, Babor T, Rehm J. Alcohol and public health. Lancet 2005;365(9458):519-30.

21. Gaunekar G, Patel V, Rane A. The impact and patterns of hazardous drinking amongst male industrial workers in Goa, India. Soc Psychiatry Psychiatr Epidemiol 2005;40(4):267-75.

22. Thara R, Padmavati R, Kumar S, Srinivasan L. Instrument to assess burden on caregivers of chronic mentally ill. Indian J Psychiatry 1998;40(1):21-9.

23. Watts M. High expressed emotion, severe mental illness and substance use disorder. Br J Nurs 2007;16(20): 1259-62

24. Mittal S, Koganti CT, Yadiyal A, Rao P, Chandini P. Expressed Emotion and Relapse of Alcohol Use Disorder. International Journal of Scientific and Research Publications 2015;5(4):1-5. 
25. Mihai A, Damsa C, Allen M, Baleydier B, Lazignac C, Heinz A. Viewing videotape of themselves while experiencing delirium tremens could reduce the relapse rate in alcohol-dependent patients. Addiction 2007;102(2):226-31.

26. Zhang MW, Ho RC. Tapping onto the Potential of Smartphone Applications for Psycho-Education and Early Intervention in Addictions. Front Psychiatry 2016;7:40.

27. Chanraud S, Martelli C, Delain F, Kostogianni N, Douaud G, Aubin HJ, Reynaud M, Martinot JL. Brain morphometry and cognitive performance in detoxified alcohol-dependents with preserved psychosocial functioning. Neuropsychopharmacology 2007;32(2):429-38.

28. Tapert SF, Brown SA, Myers MG, Granholm E. The role of neurocognitive abilities in coping with adolescent relapse to alcohol and drug use. J Stud Alcohol 1999;60(4):500-8.

29. Stephens DN, Duka T. Cognitive and emotional consequences of binge drinking: role of amygdala and prefrontal cortex. Philos Trans R Soc Lond B Biol Sci 2008;363(1507):3169-79.

30. Borlikova GG, Elbers NA, Stephens DN. Repeated withdrawal from ethanol spares contextual fear conditioning and spatial learning but impairs negative patterning and induces over-responding: evidence for effect on frontal cortical but not hippocampal function? Eur J Neurosci 2006;24(1):205-16.

31. Loeber S, Duka T, Welzel MH, Nakovics H, Heinz A, Mann K, Flor H. Effects of Repeated Withdrawal from Alcohol on Recovery of Cognitive Impairment under Abstinence and Rate of Relapse. Alcohol Alcohol 2010;45(6):541-7.

32. Levola J, Aalto M, Holopainen A, Cieza A, Pitkanen T. Health-related quality of life in alcohol dependence: a systematic literature review with a specific focus on the role of depression and other psychopathology. Nord J Psychiatry 2014;68(6):369-84.

33. Arackal BS, Benegal V. Prevalence of sexual dysfunction in male subjects with alcohol dependence. Indian J Psychiatry 2007;49(2):109-12.

34. Urbanoski KA, Kelly JF, Hoeppner BB, Slaymaker V. The role of therapeutic alliance in substance use disorder treatment for young adults. J Subst Abuse Treat 2012;43(3):344-51.

35. Wang J, Wang Y, Wei C, Yao NA, Yuan A, Shan Y, Yuan C. Smartphone interventions for long-term health management of chronic diseases: an integrative review. Telemed J E Health 2014; 20(6):570-83.

36. Baca CT, Alverson DC, Knapp-Manuel J, Blackwell GL. Telecounseling in rural areas for alcohol problems. Alcoholism Treat Quart 2007;25(4):31-45.

37. Young LB. Telemedicine interventions for substance-use disorder: a literature review. J Telemedicine Telecare 2012;18(1):47-53.

38. McKay JR, Van Horn DH, Oslin DW, Lynch KG, Ivey M, Ward K, Drapkin ML, Becher JR, Coviello D. M. (2010). A randomized trial of extended telephone-based continuing care for alcohol dependence: withintreatment substance use outcomes. J Consult Clin Psychol 2010;78(6):912-23.

Acknowledgements - The authors would like to thank Mr. Amaresha C. Anekal, Dr. Divya Sadana, Dr. Vivek Benegal, Dr. Prabhat Kumar Chand, Dr. Arun K., Dr. R. Parthasarathy, Dr. Janardhana, Dr. Kavitha Jangum, Dr. Aravind E. Raj, Dr. Anirudha Basu and Dr. Sojan Baby who have contributed immensely to the preparation of the schedule adopted for the need assessment as part of the in-depth interviews

Source of Funding - Nil

Conflict of Interest - Nil 